\title{
Pedagogos em formação: revisão sistemática das trajetórias formativas, identidades, letramento e perfil midiático
}

\author{
Pedagogues in formation: systematic review of formative \\ trajectories, identities, literacy and media profile
}

Pedagogos en formación: revisión sistemática de trayectorias formativas, identidades, alfabetización y perfil mediático

KLALter Bez Fontana ARndt iDa

DULCE MÁrCIA CRUZ (iDb

\section{Resumo}

A identidade midiática do pedagogo em formação sofre influência direta da trajetória formativa e da representação social que estes sujeitos têm sobre a profissão escolhida e na relação com as mídias em seu cotidiano. A partir dessa hipótese, o presente trabalho integra uma pesquisa de doutorado em andamento que tem por objetivo verificar e analisar o perfil midiático do pedagogo em formação, numa possível articulação da constituição deste perfil com sua trajetória formativa e com a representação social que estes sujeitos têm sobre a profissão do pedagogo. $O$ propósito deste trabalho é apresentar um retrato temporal de pesquisas já realizadas sobre trajetórias formativas, representação social, identidades, letramento e perfil midiático, evidenciando desde o detalhamento do percurso metodológico até os resultados encontrados. A metodologia usada foi a revisão sistemática e o recorte temporal foi de 10 anos (2010 a 2020), que culminou na análise atenta de 75 trabalhos, resultantes de pesquisas acadêmicas da área da educação. O resultado evidenciou a relevância de pesquisas sobre identidades e sua interface com trajetória formativa, principalmente quando os sujeitos são pedagogos em formação. Discutir sobre identidade midiática dos pedagogos requer levar em consideração a sua

\footnotetext{
a Universidade Federal de Santa Catarina (UFSC), Florianópolis, SC, Brasil. Mestre em Educação, e-mail: klalter.fontana@gmail.com

b Universidade Federal de Santa Catarina (UFSC), Florianópolis, SC, Brasil. Doutora em Engenharia de Produção, e-mail: dulce.marcia@gmail.com
} 
relação com as mídias, como estas estiveram presentes em sua trajetória formativa e como essa relação contribuiu na constituição da sua identidade.

Palavras-chave: Identidade midiática. Trajetória formativa. Representação social do pedagogo. Revisão sistemática.

\begin{abstract}
The media identity of the educator in training suffers direct influence from the formative trajectory and the social representation that these subjects have on the chosen profession and in the relationship with the media in their daily lives. From that hypothesis, this work integrates a doctoral research in progress that aims to verify and analyze the media profile of the educator in training, in a possible articulation of the constitution of this profile with his formative trajectory and with the social representation that these subjects have about the profession of the pedagogue. The purpose of this work is to present a temporal portrait of research already carried out on formative trajectories, social representation, identities, literacy and media profile, showing from the details of the methodological path to the results found. The methodology used was the systematic review and the time frame was 10 years (2010 to 2020), which culminated in the careful analysis of 75 works, resulting from academic research in the area of education. The result of this analysis showed the relevance and need for research on identities and their interface with a formative trajectory, especially when the subjects are educators in training. Discussing the media identity of pedagogues requires taking into account their relationship with the media, how they were present in their formative trajectory and how this relationship contributed to the constitution of their identity.
\end{abstract}

Keywords: Media identity. Formative trajectory. Social representation of the pedagogue. Systematic review.

\title{
Resumen
}

La identidad mediática del educador en formación sufre influencia directa de la trayectoria formativa y la representación social que estos sujetos tienen en la profesión elegida y en la relación con los medios en su vida cotidiana. Pensando en esta articulación necesaria, el presente trabajo integra una investigación doctoral en curso que tiene como objetivo verificar y analizar el perfil mediático del educador en formación, en una posible articulación de la constitución de este perfil con su trayectoria formativa y con la representación social que estos sujetos tienen sobre la profesión del pedagogo. El propósito de este trabajo es presentar un retrato temporal de la investigación ya realizada sobre trayectorias formativas, representación social, identidades, alfabetización y perfil de los medios, mostrando desde los detalles de la ruta metodológica hasta los resultados encontrados. La metodología utilizada fue la revisión sistemática y el período de tiempo fue de 10 años (2010 a 2020), que culminó en el análisis cuidadoso de 75 obras, resultado de la investigación académica en el área de la educación. El resultado de este análisis mostró la relevancia y la necesidad de investigar 
las identidades y su interfaz con una trayectoria formativa, especialmente cuando los sujetos son educadores en formación. Discutir la identidad mediática de los pedagogos requiere tener en cuenta su relación con los medios, cómo estuvieron presentes en su trayectoria formativa y cómo esta relación contribuyó a la constitución de su identidad.

Palabras clave: Identidad mediática. Trayectoria formativa. Representación social del pedagogo. Revisión sistemática.

\section{Introdução}

Muito se discute a importância de formar para as mídias, da necessidade do professor se apropriar dos multiletramentos que a mídia oferece em termos de linguagens e possibilidades cognitivas, mas pouco se trata do como a trajetória formativa desses sujeitos pode oferecer importantes indicativos sobre como trabalhar essas possibilidades no curso de graduação em Pedagogia. Essa leitura é importante até mesmo para compreender um pouco das resistências que tanto se atribui ao Pedagogo no que se refere ao uso das mídias no cotidiano da sua formação e, posteriormente, na sua prática pedagógica docente no cotidiano escolar.

Nesse sentido, acreditamos que para analisarmos o letramento midiático na formação de pedagogos é fundamental que a discussão também tenha presente o olhar para a história de vida desses sujeitos, suas trajetórias formativas e as representações sociais que estes têm sobre o ser pedagogo. É fundamental que essa relação esteja presente na discussão sobre identidades, em especial o que chamaremos de identidades midiáticas (LOSTADA, 2020) dos pedagogos.

Assim, antes de avançar na pesquisa sobre identidade midiática do pedagogo e a interface com sua trajetória formativa é necessário dedicar um tempo a essa "varredura" dentro de um tempo e espaço pré-determinado, numa forma de dar continuidade à uma caminhada já em andamento. E aqui é pertinente a realização de uma revisão sistemática.

Uma pesquisa requer, como um de seus quesitos centrais, um olhar atento para os estudos já realizados sobre a temática proposta. Esse cuidado tem tanto o propósito de validar a pesquisa em andamento quanto de mapear como pesquisas com temáticas similares foram realizadas, ou seja, quais eram seus objetivos, que metodologias predominaram e que resultados alcançaram. 
Nesse intuito, a revisão sistemática se mostra como a estratégia mais adequada de realizar esse mapeamento. Com critérios claros e bem definidos, é possível identificar quais pesquisas foram feitas, os propósitos e indagações que motivaram seus pesquisadores a realizálas, bem como perceber as lacunas que justifiquem a realização de uma nova pesquisa, naquela mesma área ou temática (SAMPAIO; MANCINI, 2002; WEBSTER, WATSON, 2002)

Assim, este trabalho apresenta um retrato temporal de pesquisas já realizadas sobre trajetórias formativas, representação social, identidades, letramento e perfil midiático, evidenciando desde o detalhamento do percurso metodológico até os resultados encontrados.

\section{Etapa Metodológica}

A revisão sistemática é uma importante estratégia científica de mapear as pesquisas e os estudos já realizados sobre uma determinada temática e/ou problemática de pesquisa. Segundo Sampaio e Mancini (2002 p. 84), “esse tipo de investigação disponibiliza um resumo das evidências relacionadas a uma estratégia de intervenção específica, mediante a aplicação de métodos explícitos e sistematizados de busca, apreciação crítica e síntese da informação selecionada”. No Quadro 1 estão detalhas as etapas percorridas:

Quadro 1 - Etapas do percurso metodológico adotado

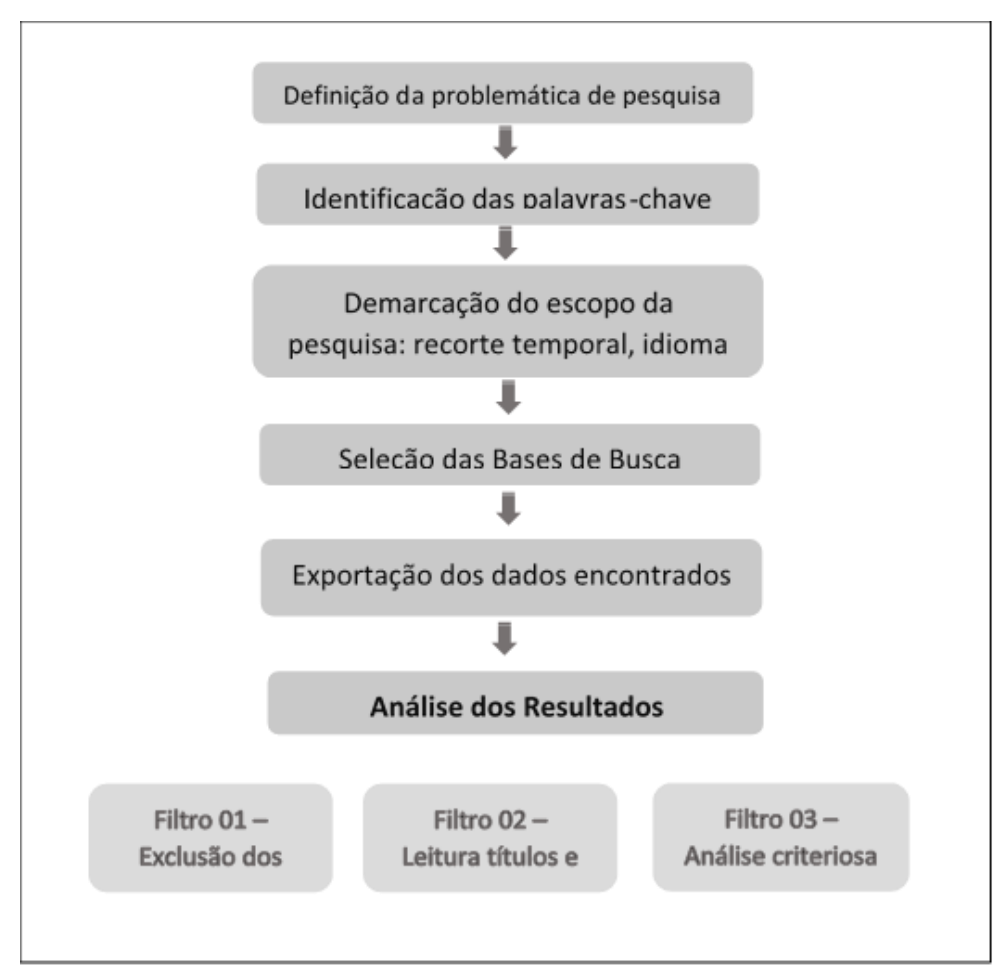

Fonte: elaborado pelas autoras (2020). 
Para que esse levantamento seja bem-sucedido, de tal forma que possa ser considerado uma revisão sistemática, é imprescindível que o mínimo de rigor científico seja aplicado. Ela precisa ser metódica, com processos transparentes e passível de ser replicada (COOK et al, 1997). E para que isso ocorra, torna-se essencial definir as etapas que constituirão esse mapeamento de tal forma que, quem desejar refazer o percurso, poderá encontrar os dados e análises similares.

Apresentamos, a seguir, o detalhamento dessas etapas, bem como os recortes realizados, os critérios de exclusão e uma análise geral dos resultados encontrados.

\section{Etapa 1: Definição da problemática de pesquisa}

O primeiro passo para iniciar uma revisão sistemática é saber qual a questão, a problemática que move a investigação. As questões presentes nos delineamentos da pesquisa foram as seguintes:

- A trajetória formativa dos alunos de pedagogia poderia influenciar o desenvolvimento da sua identidade midiática, no que tange ao uso das mídias durante sua formação e, posteriormente, na sua prática docente?

- De que forma a trajetória formativa e a representação social sobre o Pedagogo poderiam influenciar (ou até mesmo determinar) o comportamento desses alunos com relação ao uso das mídias e na construção do seu perfil midiático?

- O que já foi investigado sobre esse tripé: identidade midiática trajetória formativa - representação social do pedagogo?

Para responder, é preciso um olhar cuidadoso sobre o que já foi feito.

\section{Etapa 2: Definição das palavras-chave}

Após a delimitação da problemática, é fundamental saber quais as palavras-chave certas para serem utilizadas na busca. Essas palavras ajudam a refinar a busca ou deixá-la tão aberta e vaga que não se consegue uma busca mais precisa que venha ao encontro do escopo da investigação. A dificuldade aumenta porque a revisão coincide com o 
momento inicial da pesquisa e, portanto, a definição do escopo ainda é um desafio dentro do processo em andamento do recorte e delineamento da investigação.

Tendo em vista a problemática e a proposta teórica que irá embasar o projeto, fizemos um teste usando palavras-chave similares. Após essa testagem inicial, fizemos um refinamento das palavras, que ficaram assim definidas: Identidade Docente; Identidade Discente; Representação Social do Pedagogo; Narrativas Docentes; Histórias de Vida na formação do professor, Cultura Digital e Pedagogo, Perfil e Identidade Midiática do Professor. Importante destacar que, embora os sujeitos da pesquisa serão os estudantes de graduação de Pedagogia, ampliamos a busca incluindo a palavra "docente", já que somente o termo discente trouxe um número inexpressivo de resultados. Com a ampliação, o olhar foi mais cuidadoso na análise dos trabalhos, com seleção daqueles que convergiam ou tinham sinergia com os sujeitos da pesquisa.

As palavras-chave referentes à Narrativas e História Oral estão ligadas diretamente ao caminho metodológico que pretendemos utilizar na pesquisa, conforme proposto por autores como Josso (2004) e Nóvoa e Finger (2010). Queríamos, com estas, verificar a existência de pesquisas que já se propuseram olhar para o sujeito "Pedagogo em Formação" buscando indícios da constituição da sua identidade na sua trajetória formativa, ou seja, na sua história de vida, seguindo a mesma linha defendida por Alberti (2004), Pollack (1992) e Portelli (1997).

\section{Etapa 3: Busca na Base de Dados}

As bases utilizadas para busca foram Web of Science (SCIELO), ERIC, Google Acadêmico e Banco de Teses da CAPES. Os filtros iniciais escolhidos foram: recorte temporal de 2010 a 2020, idioma português e espanhol, artigos analisados por pares, teses, dissertações, sendo que interessavam somente pesquisas da área de humanas e/ou programas de educação. Esse recorte foi necessário para delimitarmos as pesquisas e estudos realizados na mesma área em que a nossa pesquisa está sendo feita, tendo assim proximidades conceituais e metodológicas.

Apresentamos a seguir os resultados encontrados:

a. Base Web of Science (SCIELO) 
A primeira ferramenta de busca utilizada foi a SciELO (Scientific Electronic Library) Online) que pertence à base Web of Science, considerada uma das principais bases de dados com pesquisas da área de educação. Após a busca com as palavras-chave definidas, tivemos um expressivo resultado, conforme apresentado na Tabela 1.

Tabela 1 - Resultados da busca na base Web of Science (SCIELO)

\begin{tabular}{l|l|l}
\hline Identidade docente: 118 & Identidade discente: 07 & $\begin{array}{l}\text { Representação social do } \\
\text { professor: 23 }\end{array}$ \\
\hline Narrativa docente: 76 & Perfil midiático: 05 & Identidade midiática: 03 \\
\hline $\begin{array}{l}\text { Cultura digital e professor: } \\
16\end{array}$ & Narrativa discente: 02 & $\begin{array}{l}\text { Histórias de Vida na } \\
\text { formação do professor: } 13\end{array}$ \\
\hline
\end{tabular}

Palavras-chave sem resultados: Perfil midiático do professor; Perfil midiático do pedagogo; Perfil midiático e formação do professor; Identidade discente dos alunos de Pedagogia; Identidade discente dos alunos de licenciatura

Fonte: elaborado pelas autoras (2020).

O bom retorno que obtivemos, mesmo que ainda sem uma análise apurada dos trabalhos encontrados, que foi feita num segundo momento, evidencia a importância da base de dados SCIELO para as pesquisas em educação.

b. Base ERIC

A segunda base de busca foi a ERIC (Education Resources Information Center). Nesta, os filtros permitem que mais de uma palavra-chave seja vinculada numa mesma pesquisa. A busca começou pela palavra-chave Identidade Docente, o que resultou em um número bastante expressivo: 4.699 trabalhos. Diante desse resultado, os seguintes filtros foram aplicados, com as palavras em inglês:

1. Descriptor: professional identity

2. Publication type: reports-research

3. Research: teacher atitudes; professional identity e personal narratives 
Figura 1 - Filtros aplicados na base ERIC

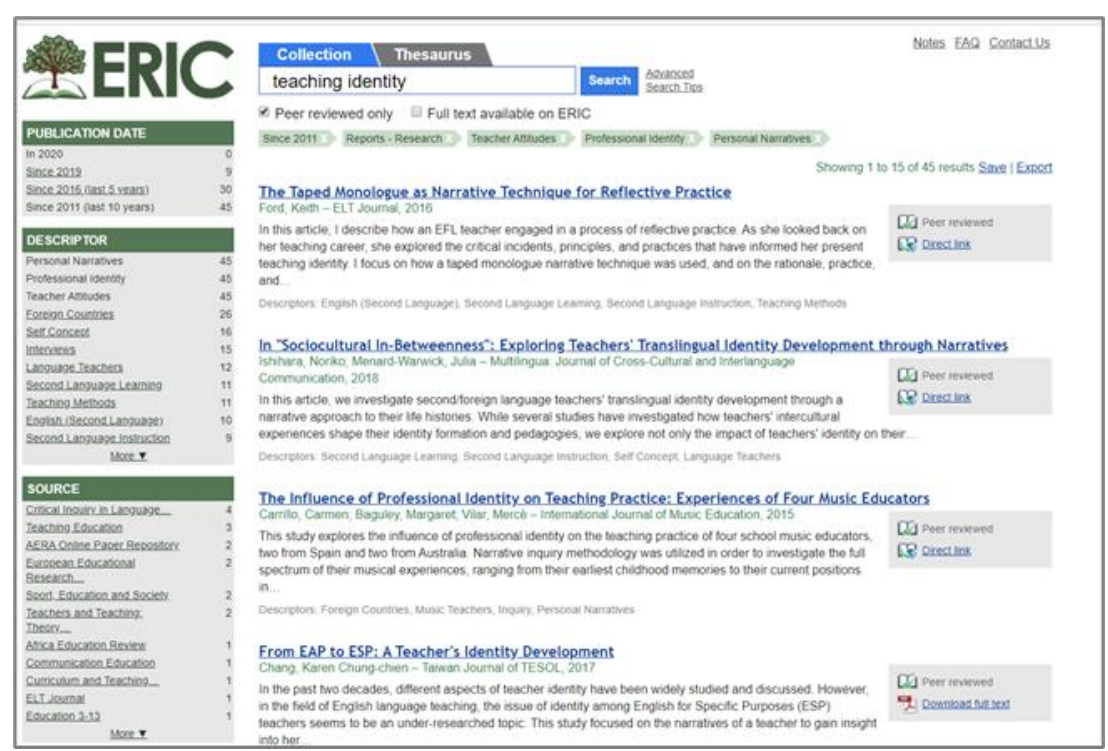

Fonte: Extraído no site da base ERIC em 05 de abril de 2020.

Após a aplicação dos filtros, o resultado apresentou 45 artigos selecionados. Essa base se mostra bastante diferente da SciELO, já que os filtros de busca são outros e permite o agrupamento de diferentes palavras-chave numa mesma busca. Isso é possível pelos filtros que vão sendo aplicados no processo de busca, antes da ferramenta mostrar o resultado final.

\section{c. Google Acadêmico}

A terceira base foi o Google Acadêmico (Tabela 2), uma base que pertence ao sistema Google e permite a busca por trabalhos específicos da área acadêmica. Nessa base, a busca pela palavra-chave Identidade Docente do Pedagogo resultou em 15.300 trabalhos. Como essa ferramenta não dispõe de filtros, foram selecionados os trabalhos cujos títulos continham as palavras "Identidade docente" e "Pedagogo". Isso resultou num total de 27 trabalhos. O que facilitou essa filtragem manual é que o Google organiza os trabalhos conforme sejam mais fidedignos às palavras colocadas na busca. Assim, os trabalhos selecionados eram os primeiros a aparecerem na listagem. A mesma situação surgiu com a busca pela palavra-chave Identidade discente, que apresentou 129 resultados. Numa análise rápida, que serviu como um filtro manual, realizamos a leitura do título e resumo dos trabalhos, e do total apresentado, somente dois trabalhos correspondiam ao propósito da nossa pesquisa. 
Tabela 2 - Resultados da busca na base Google Acadêmico

\begin{tabular}{l|l|l}
\hline Identidade docente: 10 & Identidade discente: 02 & $\begin{array}{l}\text { Representação Social do } \\
\text { Professor: 25 }\end{array}$ \\
\hline Narrativa docente: 0 & Perfil midiático: 01 & $\begin{array}{l}\text { Histórias de Vida na formação } \\
\text { do professor: } 01\end{array}$ \\
\hline
\end{tabular}

Fonte: elaborado pelas autoras (2020).

Essa terceira base se mostrou mais desafiante, já que a ausência de filtros automáticos e a impossibilidade de migrar de forma única todos os trabalhos selecionados para a ferramenta EndNotes, demandaram um trabalho mais braçal, de realização da leitura dos títulos e resumos ainda nessa fase inicial de busca. De qualquer forma, isso foi necessário, para que somente pesquisas mais alinhadas com a nossa proposta pudessem ser selecionadas.

d. Banco de Teses da CAPES

Por último, foi realizada uma busca no banco de teses da CAPES (Tabela 3). Assim como no Google Acadêmico, após apresentação dos resultados, foi necessária a leitura dos títulos e resumos para verificar o alinhamento ao nosso escopo de pesquisa.

Tabela 3 - Resultados da busca no Banco de Teses da CAPES

\begin{tabular}{l|l|l}
\hline Identidade docente: 08 & Identidade discente: 00 & $\begin{array}{l}\text { Representação Social do } \\
\text { Professor: 01 }\end{array}$ \\
\hline Narrativa docente: 00 & Perfil midiático: 00 & $\begin{array}{l}\text { Histórias de Vida na } \\
\text { formação do professor: 00 }\end{array}$ \\
\hline
\end{tabular}

Fonte: elaborado pelas autoras (2020).

Assim, na busca pela palavra-chave Identidade Docente, 62 trabalhos foram apresentados e, após breve olhar de títulos e resumos, somente oito trabalhos foram selecionados. Sendo que destes, seis pesquisas são da Universidade Aberta de Portugal, sem a disponibilização do trabalho. A busca pela palavra-chave Narrativa docente resultou em 21 trabalhos, mas que em breve análise de filtragem (leitura dos títulos e dos resumos), nenhuma se aplicou ao escopo da pesquisa.

O levantamento nessas quatro bases de dados se mostrou fundamental para a realização da revisão sistemática. Embora nesse primeiro momento, não tínhamos como objetivo identificar duplicidades de trabalhos, os resultados apresentaram uma boa amostragem de pesquisas realizadas com temáticas similares ao da nossa pesquisa. 
Consideramos, também, que as quatro bases abarcam as principais ferramentas de busca na área da educação, não sendo necessária a inclusão de outras. Após, passamos às etapas seguintes, que serviram como refinamento progressivo dos trabalhos coletados.

\section{Etapa 4: Importação dos trabalhos para a ferramenta EndNotes}

Essa etapa resultou no agrupamento de todos os trabalhos encontrados nas bases reunidos por palavras-chave e a identificação de trabalhos duplicados. Dentre os softwares de gerenciamento de bibliografias, escolhemos o EndNotes (desenvolvido pela Clarivate Analytics/USA), por já termos a licença e formação no uso (Figura 2).

Figura 2 - Ferramenta EndNotes após importação dos trabalhos encontrados nas bases de pesquisa

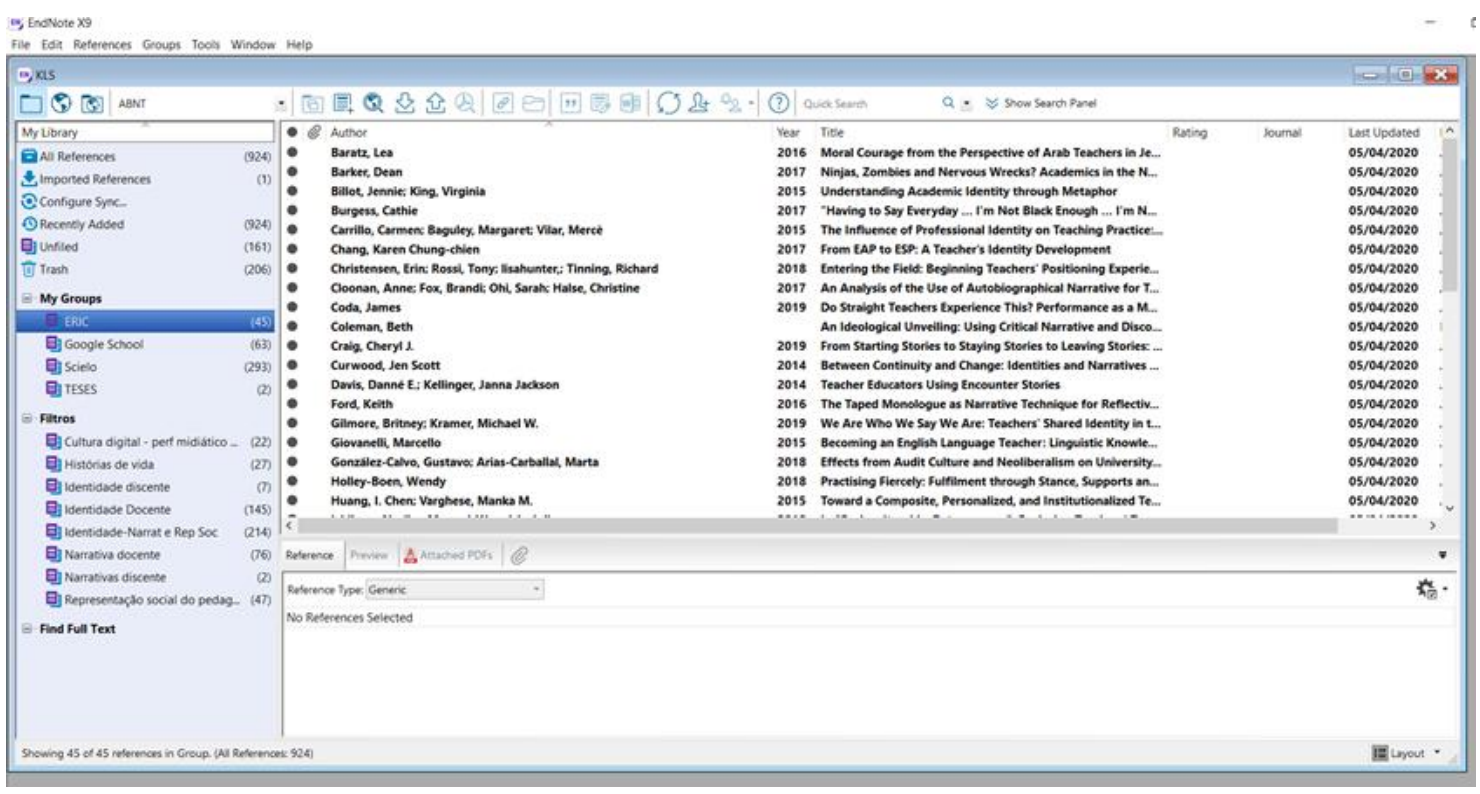

Fonte: Template do EndNotes - elaborado pelas autoras (abril, 2020).

Após a inclusão de todos os trabalhos no EndNotes e exclusão dos duplicados, contamos ao final, com 327 textos, que foram analisados com acuidade, para além da leitura de títulos e resumos.

\section{Etapa 05: Triagem dos resultados encontrados}

Com a quantidade enorme de trabalhos, tornou-se necessário aplicar um primeiro filtro: seleção com base na leitura dos títulos e resumos. Assim, foi possível 
verificar se o escopo dos dados levantados tinha relação com nossa pesquisa, servindo ao propósito da revisão sistemática. Para tanto, tornou-se necessário relacionar alguns pontos que seriam usados para exclusão dos textos:

1. Trabalhos sobre identidade, voltados para análise profissional da docência, tendo como sujeitos da pesquisa professores já em exercício e análise do processo de profissionalização docente com base nas reformas educacionais.

2. Trabalhos sobre identidade, tendo como foco a análise do curso da Pedagogia, do currículo desses cursos e a relação teoria-prática na formação docente.

3. Trabalhos sobre identidade voltados para a análise da docência no ensino superior e/ou relacionados às outras áreas da docência, que não a Pedagogia.

4. Pesquisas sobre profissionalização docente com foco nas reformas educacionais, com análise de cunho político, ligadas a pesquisas historiográficas.

5. Pesquisas sobre representação social de professores, mas com recorte de análise sobre áreas em que atuam (ciências, história etc.), voltadas para professores já atuantes, e de áreas que não das licenciaturas (aqui foi permitido a inclusão de outras áreas, especificamente nos trabalhos que fizeram uso das narrativas, memórias e trajetórias formativas na sua metodologia, desde que de trabalhos próximos aos objetivos desta pesquisa).

6. Pesquisas voltadas à identidade docente/discente e representação social da docência, mas com análises voltadas para etnias, raças, gênero e questões indígenas.

7. Textos que discutiam o uso das mídias ou a cultura digital com Pedagogos em exercício (sua utilização em sala de aula na Educação Básica) ou voltadas para a EaD.

8. Trabalhos utilizando a metodologia das narrativas e histórias de vida, mas com pesquisas voltadas para outros sujeitos que não os graduandos da Pedagogia, processos de aprendizagem na Educação Básica, 
professores em exercício, docência no ensino superior e alunos do ensino médio.

Assim, após leitura e análise do resumo de todos os trabalhos, ficamos com um total de 71 textos, entre artigos, teses e dissertações, distribuídos conforme a Tabela 4:

Tabela 4 - Levantamento das pesquisas, após análise dos títulos e resumos

\begin{tabular}{l|l}
\hline Palavra-chave & Quantidade de trabalhos \\
\hline Identidade docente do professor & 24 \\
\hline Representação social do pedagogo & 21 \\
\hline Histórias de vida & 5 \\
\hline Identidade discente & 0 \\
\hline Perfil midiático e cultura digital do professor & 9 \\
\hline Narrativas discentes & 0 \\
\hline Narrativas docentes & 12 \\
\hline TOTAL & 71 \\
\hline
\end{tabular}

Fonte: elaborado pelas autoras (2020).

\section{Etapa 6: Análise dos trabalhos selecionados}

Nesta etapa buscamos verificar o escopo das pesquisas realizadas, seus sujeitos, objetivos e resultados, e, com isso, perceber o quão estavam próximos (ou não) do escopo e problemática da nossa pesquisa. Para isso, todos os trabalhos foram exportados para um arquivo Excel, onde foram analisados e registrados nas seguintes categorias: autor, título, ano, tipo de publicação, palavras-chave, sujeitos/objeto de pesquisa, objetivo, metodologia e resultados.

Durante a leitura, alguns artigos foram excluídos, quando percebemos que fugiam totalmente do escopo inicial (impossível de perceber pela leitura somente do resumo) e por duplicidade (por exemplo: mesmo trabalho, um na versão tese e outro na versão artigo). Neste caso optamos pelo artigo, já que apresenta a consolidação objetiva da pesquisa realizada.

$\mathrm{Na}$ Tabela 5 apresentamos uma breve síntese do que encontramos nas pesquisas, agrupadas pelas palavras-chave com as quais foram identificadas. 
Tabela 5 - Resultado final dos trabalhos que integraram a Revisão Sistemática

\begin{tabular}{l|l}
\hline Palavra-chave & Quantidade de trabalhos \\
\hline Identidade docente do professor & 19 \\
\hline Representação social do pedagogo & 17 \\
\hline Histórias de vida & 5 \\
\hline Identidade discente & 0 \\
\hline Perfil midiático e cultura digital do professor & 9 \\
\hline Narrativas discentes & 0 \\
\hline Narrativas docentes & 10 \\
\hline TOTAL & 60 \\
\hline
\end{tabular}

Fonte: elaborado pelas autoras (2020)

Dos nove trabalhos analisados sobre "Perfil midiático e cultura digital", nenhum teve como foco identificar o perfil midiáticos dos estudantes de Pedagogia buscando elementos da sua trajetória formativa. O foco destes trabalhos é a discussão sobre mídias na formação de professores, numa preparação para a prática docente. $\mathrm{O}$ perfil midiático aparece nessas pesquisas, mas identificadas por meio de questionários, num levantamento mais quantitativo, identificando acesso a recursos e uso das linguagens midiáticas (CASTRO BARBOSA et al, 2018; ROCHA, 2016; PONTES, 2016). Dois desses tiveram como foco o uso das redes sociais por estudantes de licenciatura, numa análise articulada à cultura digital (AYALA PÉREZ, 2015; RUEDA ORTIZ, 2017). Outros dois buscaram uma discussão sobre a cultura digital e como os novos letramentos se fazem presente na formação dos professores, podendo refletir (ou não) em sua prática profissional docente (CERUTTI, 2014; PONTES, 2016). E por fim, dois trabalhos tiveram como sujeitos professores já em exercício (BATISTA, 2012; LOSTADA, 2020), sendo que um deles fez uso das narrativas como metodologia de pesquisa (LOSTADA, 2020). Na Tabela 6 apresentamos os trabalhos analisados. 
Tabela 6 - Trabalhos selecionados sobre Perfil Midiático/Cultura Digital

\begin{tabular}{|c|c|c|c|}
\hline AUTORES & ANO & TÍTULO & TIPO \\
\hline $\begin{array}{l}\text { de Castro } \\
\text { Barbosa, J. } \\
\text { et al. }\end{array}$ & 2018 & $\begin{array}{l}\text { A formação do pedagogo (a) e o uso das Redes Sociais na } \\
\text { sociedade contemporânea: um estudo de caso no curso de } \\
\text { Pedagogia da Universidade Federal do Ceará-UFC }\end{array}$ & Artigo \\
\hline $\begin{array}{l}\text { Rueda Ortiz, } \\
\text { R. }\end{array}$ & 2017 & $\begin{array}{l}\text { Subjetividad y tecnologías de la escritura. La formación en } \\
\text { tiempos de poshumanismo }\end{array}$ & Artigo \\
\hline Rocha, B. M. & 2016 & $\begin{array}{l}\text { Letramento midiático nas licenciaturas: um estudo com } \\
\text { estudantes do curso de Pedagogia da Universidade } \\
\text { Federal de Santa Catarina }\end{array}$ & TCC \\
\hline Pontes, E. L. F & 2016 & Cultura digital na formação inicial de pedagogos & Dissertação \\
\hline Cruz, D. M. & 2016 & $\begin{array}{l}\text { Letramentos, práticas pedagógicas e formação de } \\
\text { professores para as mídias: reflexões sobre a relação entre } \\
\text { a cultura digital e a universidade }\end{array}$ & Artigo \\
\hline $\begin{array}{l}\text { Ayala Pérez, } \\
\text { T. C. }\end{array}$ & 2015 & $\begin{array}{l}\text { Redes sociales e hiperconectividad en futuros profesores } \\
\text { de la generación digital }\end{array}$ & Artigo \\
\hline Cerutti, E. & 2014 & $\begin{array}{l}\text { Concepções do aluno em relação à docência nos cursos de } \\
\text { licenciatura em tempos de cibercultura }\end{array}$ & Tese \\
\hline Batista, S. R. & 2012 & $\begin{array}{l}\text { Um diálogo entre comunicação e educação: a formação } \\
\text { inicial de professores em sociedades midiáticas }\end{array}$ & Tese \\
\hline $\begin{array}{l}\text { Lostada, L. } \\
\text { R. }\end{array}$ & 2020 & $\begin{array}{l}\text { A Jrnada do Herói e a Identidade Midiática Docente no } \\
\text { contexto da Cultura Digital }\end{array}$ & Tese \\
\hline
\end{tabular}

Fonte: elaborado pelas autoras (abril, 2020).

No geral, essas pesquisas concluíram que os cursos de formação de professores ainda carecem de ofertar uma boa base de discussão sobre as mídias, cultura digital e os novos letramentos. As pesquisas evidenciaram que não basta ter acesso aos recursos tecnológicos ou ser nativo digital ${ }^{3}$, os cursos de formação precisam preparar os futuros professores para uso de tais recursos e linguagens em suas práticas pedagógicas, indo além da concepção limitada de conceber a mídia e as tecnologias em geral, como meros recursos de suporte às aulas (LOSTADA, 2020; PONTES, 2016; ROCHA, 2016). Outro ponto importante apontado nas pesquisas é que os professores em formação têm acesso às tecnologias digitais, mas o uso é voltado muito mais para o entretenimento, ou seja, não se sentem preparados para uso pedagógico das mídias e suas linguagens no cotidiano educacional (BARBOSA et al, 2018). Nessas pesquisas, os sujeitos investigados sentem que o curso de Pedagogia não

\footnotetext{
${ }^{3}$ A expressão "nativos digitais" surgiu em 2001, criada por Marc Prensky, especialista estadunidense em educação. Ele designou como nativos digitais todos os nascidos após 1980, cujo crescimento se deu em contato direto com as tecnologias.
} 
prepara para esse uso das mídias no cotidiano das escolas, sendo urgente a necessidade de eventos de letramento midiáticos e reflexão crítica do uso das linguagens multimodais.

No que tange aos estudos sobre perfil midiático na formação de pedagogos, os trabalhos analisados não apontam a discussão desse perfil atrelada à trajetória formativa desses graduandos, considerando sua história de vida e a própria representação social que têm sobre o ser pedagogo. Outro aspecto importante é a ausência de pesquisas que buscam investigar como os estudantes de pedagogia (ou licenciatura em geral), podem se apropriar da linguagem midiática no seu processo formativo, como os novos letramentos impactam o seu cotidiano como estudante, o seu processo de aprendizagem.

Os trabalhos relacionados à temática Identidade Docente em geral resultaram de estudos teóricos, voltados para revisão bibliográfica e estudo conceitual (ALMEIDA et al., 2019; GORZONI; DAVIS, 2017; GONÇALVES, 2016; DINIZ-PEREIRA, 2016; IZA et al., 2014; GONZALES et al., 2014; DOMINSCHEK; WALOSKI, 2013; OLIVEIRA, 2012; FARIA; FARIA \& SOUZA, 2011; BRZEZINSKI, 2011). Essas pesquisas são oriundas de estudos que investigaram o conceito de identidade docente na literatura e em publicações realizadas num determinado período. São discussões importantes, mas que não têm como foco a constituição da identidade docente numa articulação com sua trajetória formativa e nem com a constituição de um perfil midiático. Outros oito trabalhos tiveram como sujeitos alunos da Pedagogia ou professores em exercício, mas o estudo sobre identidades teve aspectos diferenciados, seja sobre trajetórias de egressas de curso de graduação em Pedagogia a Distância (VENTURA, 2018), profissão docente e escolha de carreira (GONÇALVES, 2010; SALES; CHAMON, 2011; CARVALHO, 2012; MARTINS; ANUNCIATO, 2018; MALACRIDA et al., 2013), questões religiosas e de gênero na identidade docente (KNOBLAUCH, 2017); comunidades on-line (MARTINS; ANUNCIATO, 2018) e identidade docente de professores da língua inglesa (BALADELI et al., 2016). $\mathrm{Na}$ Tabela 7 apresentamos os 19 trabalhos analisados: 
Tabela 7 - Trabalhos selecionados sobre Identidade Docente

\begin{tabular}{|c|c|c|c|}
\hline AUTORES & ANO & TÍTULO & TIPO \\
\hline $\begin{array}{l}\text { Almeida, S. R. D. et } \\
\text { al. }\end{array}$ & 2019 & $\begin{array}{l}\text { Identidade docente com foco no cenário de } \\
\text { pesquisa: uma revisão sistemática }\end{array}$ & Artigo \\
\hline $\begin{array}{l}\text { Martins, R. M. and } \\
\text { Anunciato, R. M. M. }\end{array}$ & 2018 & $\begin{array}{l}\text { Caminhos de aprendiz de professora: processos } \\
\text { identitários em uma comunidade de aprendizagem online }\end{array}$ & Artigo \\
\hline $\begin{array}{l}\text { Gorzoni, S. D. P. and } \\
\text { Davis, C. }\end{array}$ & 2017 & $\begin{array}{l}\text { O conceito de profissionalidade docente nos } \\
\text { estudos mais recentes }\end{array}$ & Artigo \\
\hline $\begin{array}{l}\text { Diniz-Pereira, J. E. J. } \\
\text { E. e. P. }\end{array}$ & 2016 & $\begin{array}{l}\text { Lentes teóricas para o estudo da construção da } \\
\text { identidade docente }\end{array}$ & Artigo \\
\hline $\begin{array}{l}\text { Baladeli, A. P. D. et } \\
\text { al. }\end{array}$ & 2016 & $\begin{array}{l}\text { Identidades docentes e diferença no discurso de } \\
\text { professores de Língua Inglesa em formação inicial }\end{array}$ & Artigo \\
\hline Iza, D. F. V. et al. & 2014 & $\begin{array}{l}\text { Identidade docente: as várias faces da } \\
\text { constituição do ser professor }\end{array}$ & Artigo \\
\hline $\begin{array}{l}\text { Gonzales, N. V. L. et } \\
\text { al. }\end{array}$ & 2014 & $\begin{array}{l}\text { Os Decursos Históricos, Culturais e Legais da Constituição } \\
\text { da Identidade Profissional do Pedagogo no Brasil }\end{array}$ & Artigo \\
\hline $\begin{array}{l}\text { Malacrida, V. A. et } \\
\text { al. }\end{array}$ & 2013 & $\begin{array}{l}\text { A identidade do curso de pedagogia: uma } \\
\text { investigação via história oral }\end{array}$ & Artigo \\
\hline $\begin{array}{l}\text { Dominschek, D. L. } \\
\text { and Waloski, L. J. R. I. }\end{array}$ & 2013 & $\begin{array}{l}\text { A identidade do pedagogo escolar: notas } \\
\text { introdutórias }\end{array}$ & Artigo \\
\hline $\begin{array}{l}\text { Oliveira, D. A. J. R. d. } \\
\text { e. }\end{array}$ & 2012 & $\begin{array}{l}\text { O trabalho docente na América Latina: } \\
\text { identidade e profissionalização }\end{array}$ & Artigo \\
\hline $\begin{array}{l}\text { de Carvalho, R. C. } \\
\text { M. }\end{array}$ & 2012 & $\begin{array}{l}\text { Formação e constituição da identidade docente } \\
\text { de licenciandos de um curso de pedagogia }\end{array}$ & Dissertação \\
\hline Borges, F. T. & 2012 & $\begin{array}{l}\text { A professora que vemos nos filmes: construção } \\
\text { identitária e significados da docência }\end{array}$ & Artigo \\
\hline $\begin{array}{l}\text { Sales, A. d. C. M. and } \\
\text { Chamon, E. M. Q. d. O. }\end{array}$ & 2011 & $\begin{array}{l}\text { Escolha da carreira e processo de construção da } \\
\text { identidade profissional docente }\end{array}$ & Artigo \\
\hline $\begin{array}{l}\text { Faria, E. d. and } \\
\text { Souza, V. L. T. }\end{array}$ & 2011 & $\begin{array}{l}\text { Sobre o conceito de identidade: apropriações em } \\
\text { estudos sobre formação de professores }\end{array}$ & Artigo \\
\hline $\begin{array}{l}\text { Cruz, F. M. L. and de } \\
\text { Aguiar, M. d. C. C. }\end{array}$ & 2011 & $\begin{array}{l}\text { Trajetórias na identidade profissional docente: } \\
\text { aproximações teóricas }\end{array}$ & Artigo \\
\hline Brzezinski, I. J. R. U. & 2011 & Pedagogo: delineando identidade (s) & Artigo \\
\hline Gonçalves, L. d. S. & 2010 & $\begin{array}{l}\text { O curso de pedagogia e o processo de } \\
\text { construção da identidade do pedagogo }\end{array}$ & Dissertação \\
\hline Ventura, L. & 2019 & $\begin{array}{l}\text { O Voo da Fênix: narrativas de travessias de } \\
\text { identidade de egressas de educação a distância }\end{array}$ & Tese \\
\hline Gonçalves, K. A. & 2016 & Identidade docente nos artigos da ANPEd - 2010/2014 & Artigo \\
\hline
\end{tabular}

Fonte: elaborado pelas autoras (abril 2020).

As pesquisas empíricas versaram sobre como os sujeitos investigados percebiam a construção identitária do ser professor, na maioria das vezes ainda relacionada com a profissão que irão atuar após formados, ou seja, uma discussão sobre identidade docente voltada à identidade profissional dessa atividade. Outro aspecto que apareceu nos textos foi como o curso de Pedagogia contribui na constituição identitária desses sujeitos com a profissão escolhida. Somente um trabalho buscou trazer a articulação entre identidade docente e imaginário social por meio da análise de dois filmes, que tinham como personagem central um professor (BORGES, 2012). As estratégias metodológicas versaram entre estudos teóricos e 
revisão bibliográfica (para os estudos teóricos) e aplicação de questionários e entrevistas semi-estruturadas, para as demais pesquisas.

Importante destacar que três pesquisas fizeram uso de narrativas (auto)biográficas e histórias de vida como metodologia (VENTURA, 2018; MARTINS; ANUNCIATO, 2018; MALACRIDA et al., 2013). Embora tenham sido trabalhos relevantes quanto ao uso de narrativas, o foco dessas pesquisas não foi trazer elementos da trajetória formativa dos alunos de Pedagogia, ou seja, da história de vida desses sujeitos anterior à entrada na graduação, no tange à constituição de sua identidade midiática.

No geral, os trabalhos evidenciaram em seus resultados a presença da linha tênue entre identidade profissional (e as precarizações que envolvem a profissão) e identidade missionária da docência, revelando uma identidade docente em construção. Uma visão de identidade bastante atrelada à profissão, e na constituição de saberes e competências necessárias para seu exercício, visão da identidade do pedagogo como um profissional generalista, também estiveram presentes em alguns textos. É necessário destacar que os resultados das pesquisas apontam que o conceito de pedagogia ainda sofre de uma dispersão semântica e que há a necessidade de pesquisas que busquem articular as questões sociológicas e psicológicas da trajetória do sujeito com a constituição da sua identidade docente. E reforçam a importância dos cursos de formação inicial na constituição da identidade docente desses pedagogos em formação.

Nos trabalhos selecionados sob a ótica das Narrativas, percebemos que houve um misto entre trabalhos teóricos e metodológicos. Os textos do primeiro grupo (SERODIO; PRADO, 2017; LIMA et al., 2015; DALMASO et al., 2015; SILVA; SIRGADO; TAVIRA, 2012; FISCHMAN; SALES, 2010) tiveram como proposta fazer uma discussão teórica sobre o uso de narrativas em pesquisas e a importância das narrativas e seus memoriais na constituição do perfil e identidade docente. Os trabalhos que usaram as narrativas numa perspectiva metodológica tiveram enfoques diferenciados, embora os sujeitos tenham sido pedagogos (em formação ou já atuantes na prática profissional). Um deles é um estudo histórico, voltado à constituição da profissão docente em São Paulo, na primeira metade do século XX, partindo da trajetória da professora paulista Botyra Camorim (ALCÂNTARA, 2012). 
Outra pesquisa foi voltada ao adoecimento de professores (BARROS et al., 2018). Temos ainda um trabalho dedicado às memórias de professoras de cursos de licenciatura (ROSA; PAVAN, 2011). Por último, encontramos um trabalho que discorreu sobre a oferta de uma disciplina no curso de graduação que fez uso de memoriais e da trajetória de vida, como possibilidades formativas (ABRAHÃO, 2011). Abaixo, a Tabela 8 traz a visão geral dos trabalhos selecionados:

Tabela 8 - Trabalhos selecionados sobre Narrativas

\begin{tabular}{|c|c|c|c|}
\hline AUTORES & ANO & TÍTULO & TIPO \\
\hline $\begin{array}{l}\text { Barros, M. E. B. d. et } \\
\text { al. }\end{array}$ & 2018 & $\begin{array}{l}\text { Narrativas da docência: dimensão sensível do } \\
\text { trabalho de professores e pesquisadores }\end{array}$ & Artigo \\
\hline $\begin{array}{l}\text { Serodio, L. A. and } \\
\text { Prado, G. d. V. T. }\end{array}$ & 2017 & $\begin{array}{l}\text { ESCRITA-EVENTO NA RADICALIDADE DA } \\
\text { PESQUISA NARRATIVA }\end{array}$ & Artigo \\
\hline Knoblauch, A. & 2017 & $\begin{array}{l}\text { Religião, formação docente e socialização de } \\
\text { gênero }\end{array}$ & Artigo \\
\hline $\begin{array}{l}\text { Lima, M. E. C. d. C. } \\
\text { et al. }\end{array}$ & 2015 & $\begin{array}{l}\text { O TRABALHO COM NARRATIVAS NA } \\
\text { INVESTIGAÇÃO EM EDUCAÇÃO }\end{array}$ & Artigo \\
\hline Dalmaso, A. C. et al. & 2015 & $\begin{array}{l}\text { Ser-se rio, vento, mulher, e o que quiser: a } \\
\text { individuação e a formação de professores }\end{array}$ & Artigo \\
\hline Silva, D. N. H. et al. & 2012 & $\begin{array}{l}\text { Memória, narrativa e identidade profissional: } \\
\text { analisando memoriais docentes }\end{array}$ & Artigo \\
\hline Alcântara, W. R. R. & 2012 & $\begin{array}{l}\text { A sala de aula foi o meu mundo: a carreira do } \\
\text { magistério em São Paulo (1920-1950) }\end{array}$ & Artigo \\
\hline $\begin{array}{l}\text { Rosa, M. I. P. and } \\
\text { Pavan, A. C. }\end{array}$ & 2011 & $\begin{array}{l}\text { Discursos híbridos nas memórias das } \\
\text { licenciaturas em ciências em uma instituição } \\
\text { universitária }\end{array}$ & Artigo \\
\hline $\begin{array}{l}\text { Abrahão, M. H. M. } \\
\text { B. }\end{array}$ & 2011 & $\begin{array}{l}\text { Memoriais de formação: a (re) significação das } \\
\text { imagens-lembranças/recordações-referências } \\
\text { para a pedagoga em formação }\end{array}$ & Artigo \\
\hline $\begin{array}{l}\text { Fischman, G. E. and } \\
\text { Sales, S. R. }\end{array}$ & 2010 & $\begin{array}{l}\text { Formação de professores e pedagogias críticas: é } \\
\text { possível ir além das narrativas redentoras? }\end{array}$ & Artigo \\
\hline
\end{tabular}

Fonte: elaborado pelas autoras (abril, 2020).

Em todas essas pesquisas ficou evidenciada a importância dos trabalhos com narrativas junto aos professores, pois possibilitam que a própria trajetória desses sujeitos sirva como objeto de reflexão e formação, numa busca pela tomada consciência de si. No entanto, nas pesquisas que usaram as narrativas como estratégia, somente uma teve como sujeito os graduandos em Pedagogia (ABRAHÃO, 2011). Em todos os resultados, as pesquisas evidenciaram a riqueza de trabalhos com narrativas, que revelam importantes elementos constituintes das identidades pessoais e profissionais dos professores. Como referencial teórico, Walter Benjamim, MarieChristine Josso e Bachelard foram referenciados. 
Nos trabalhos levantados a partir da palavra-chave Representação Social do Pedagogo, a representação social apareceu como metodologia via a Teoria das Representações Sociais, baseada principalmente nos estudos de Moscovici (2011). Selecionamos para análise 17 trabalhos, e é importante destacar que somente um teve sua metodologia voltada para cunho teórico (FIGUEIREDO; BONINI, 2017). Os demais tiveram como sujeitos de pesquisa estudantes de graduação em Pedagogia (BRANDÃO; PARDO, 2016; ARAÚJO; MAGALHÃES JUNIOR, 2016; SOUZA, 2015; MAIA; BARRETO, 2014; CHAMON, 2014; MANDÚ, 2013; BASÍLIO; MACHADO, 2013; LIMA et al., 2012; GENTILE et al., 2011; DANTAS, 2011; GEBRAN et al., 2015). Os demais trabalhos tiveram como sujeitos professores já em exercício, sejam eles pedagogos ou demais licenciados, da educação básica (NETO, 2010; SARAIVA; DE AQUINO, 2011; MIRANDA, 2012; SIPPE, 2018) e do ensino superior (SILVA; BONFIM, 2018). Apresentamos a seguir os trabalhos selecionados para análise:

Tabela 9 - Trabalhos selecionados sobre Representação Social do Pedagogo

\begin{tabular}{|c|c|c|c|}
\hline AUTORES & ANO & TÍTULO & TIPO \\
\hline Sippe, F. E. & 2018 & $\begin{array}{l}\text { Produção de sentidos sobre a construção da identidade } \\
\text { social do pedagogo: relatos de educadores }\end{array}$ & TCC \\
\hline $\begin{array}{l}\text { Figueiredo, D. } \\
\text { d. C.; Bonini, A. }\end{array}$ & 2017 & $\begin{array}{l}\text { Recontextualização e sedimentação do discurso e da } \\
\text { prática social: como a mídia constrói uma representação } \\
\text { negativa para o professor e para a escola pública }\end{array}$ & Artigo \\
\hline $\begin{array}{l}\text { Brandão, D. F.; } \\
\text { Pardo, M. B. L. }\end{array}$ & 2016 & O interesse de estudantes de pedagogia pela docência & Artigo \\
\hline $\begin{array}{l}\text { Araújo, J. L. D. } \\
\text { et al }\end{array}$ & 2016 & $\begin{array}{l}\text { As representações sociais de graduandos no curso de } \\
\text { Pedagogia sobre o ser professor" de ciências nos anos iniciais" }\end{array}$ & Artigo \\
\hline $\begin{array}{l}\text { Souza, P. R. F. } \\
\text { d. }\end{array}$ & 2015 & $\begin{array}{l}\text { A Representação Social da docência pelos alunos do curso de } \\
\text { Pedagogia da Faculdade de Educação da Universidade Federal } \\
\text { do Amazonas: um diálogo com Bourdieu em um estudo do } \\
\text { percurso no processo de formação }\end{array}$ & Tese \\
\hline $\begin{array}{l}\text { Maia, D. L. and } \\
\text { Barreto, M. C. }\end{array}$ & 2014 & $\begin{array}{l}\text { Ensinar Matemática com Uso de Tecnologias Digitais: qual } \\
\text { a Representação Social de pedagogos em formação? }\end{array}$ & Artigo \\
\hline $\begin{array}{l}\text { Chamon, E. M. } \\
\text { Q.d. O. }\end{array}$ & 2014 & $\begin{array}{l}\text { Representações sociais da formação docente em } \\
\text { estudantes e professores da Educação Básica }\end{array}$ & Artigo \\
\hline $\begin{array}{l}\text { MANDÚ, T. M. } \\
\text { C. }\end{array}$ & 2013 & $\begin{array}{l}\text { Representações sociais do campo de atuação do } \\
\text { pedagogo pelos estudantes de pedagogia }\end{array}$ & Dissertação \\
\hline $\begin{array}{l}\text { Basílio, M. A. T.; } \\
\text { Machado, L. B. }\end{array}$ & 2013 & $\begin{array}{l}\text { O CURSO DE PEDAGOGIA: nas representações sociais de } \\
\text { estudantes em formação }\end{array}$ & Artigo \\
\hline $\begin{array}{l}\text { Miranda, M. d. } \\
\text { C. G. d. }\end{array}$ & 2012 & $\begin{array}{l}\text { Formação de pedagogos em serviço a distância: } \\
\text { representações de professores/aprendentes do curso de } \\
\text { pedagogia a distância da UFPB Virtual }\end{array}$ & Tese \\
\hline $\begin{array}{l}\text { Lima, R. d. C. P. } \\
\text { et al. }\end{array}$ & 2012 & $\begin{array}{l}\text { Representações sociais de estudantes de pedagogia } \\
\text { sobre o trabalho docente em sua trajetória de formação }\end{array}$ & Artigo \\
\hline
\end{tabular}


Tabela 9 - Trabalhos selecionados sobre Representação Social do Pedagogo

(conclusão)

\begin{tabular}{l|l|l|l}
\hline AUTORES & ANO & TíTULO & TIPO \\
\hline $\begin{array}{l}\text { Saraiva, A. C. L. } \\
\text { C.; de Aquino, } \\
\text { S. L. }\end{array}$ & 2011 & $\begin{array}{l}\text { O pedagogo e seus espaços de atuação nas } \\
\text { Representações Sociais de egressos do Curso de } \\
\text { Pedagogia }\end{array}$ & Artigo \\
\hline $\begin{array}{l}\text { Gentile, M. et } \\
\text { al. }\end{array}$ & 2011 & $\begin{array}{l}\text { Saberes da prática na formação: representações sociais de alunas de } \\
\text { pedagogia }\end{array}$ & Artigo \\
\hline Dantas, L. S. C. & 2011 & $\begin{array}{l}\text { O fazer docente: representações sociais de alunos de } \\
\text { curso de pedagogia da UFRN }\end{array}$ & Dissertação \\
\hline $\begin{array}{l}\text { Almeida Neto, } \\
\text { A. S. d. }\end{array}$ & 2010 & $\begin{array}{l}\text { Dimensão utópica nas representações sobre o ensino de } \\
\text { história: memórias de professores }\end{array}$ & Artigo \\
\hline $\begin{array}{l}\text { Gebran, R. A. et } \\
\text { al. }\end{array}$ & 2015 & $\begin{array}{l}\text { As representações sociais e expectativas dos alunos } \\
\text { ingressantes no curso de Pedagogia }\end{array}$ & Artigo \\
\hline $\begin{array}{l}\text { Silva, S. S. L. da; } \\
\text { Bonfim, M. N. } \\
\text { B. }\end{array}$ & 2018 & $\begin{array}{l}\text { Representações Sociais e Identidade Doc ente: um estudo } \\
\text { com professores-alunos do PROFEBPAR/UFMA }\end{array}$ & Artigo \\
\hline
\end{tabular}

Fonte: elaborado pela autora (abril de 2020).

Em geral, os trabalhos tiveram como objetivo verificar a representação social que os sujeitos tinham sobre a atuação profissional do Pedagogo, o interesse pela docência, a representação do professor construída pela mídia (FIGUEIREDO; BONINI, 2017). Três pesquisas estavam voltadas para a representação social do pedagogo em ser docente em áreas específicas, tais como Ciências (ARAÚJO et al, 2016), Matemática (MAIA; BARRETO, 2014) e História (ALMEIDA NETO, 2010), ou seja, qual a representação eles tinham sobre atuar nessas disciplinas. Os resultados apresentados, em geral, mostraram inquietações dos pedagogos em formação sobre o fazer docente, as lacunas do curso de Pedagogia que corroboram na representação social que os estudantes têm sobre o curso e o exercício da profissão. De certa forma, o conjunto das pesquisas mostra a necessidade de um olhar mais atento para as representações sociais construídas sobre a figura do pedagogo. Influência da família, gostar de criança e o interesse desde pequenos pela profissão, são ainda elementos bastante fortes na representação que estes sujeitos têm do Pedagogo e que influenciam na escolha pela profissão.

Os trabalhos levantados na busca pela palavra-chave Histórias de Vida evidenciaram o uso desta estratégia para compreender as subjetividades presentes nas trajetórias de vida dos sujeitos entrevistados e para entender o processo de profissionalização. Dos cinco trabalhos selecionados para análise, dois tinham como 
sujeitos de pesquisa os graduandos em Pedagogia (BERGAMASCHI; ALMEIDA, 2013; CINTRA; ALBANO, 2010) e em outros três a investigação se deu a partir de conversas com professores já em exercício profissional (ECKERT-HOFF, 2015; ALMEIDA; SOARES, 2012; LUNA, 2010). Abaixo a Tabela $10 \mathrm{com}$ os cinco trabalhos selecionados:

Tabela 10 - Trabalhos selecionados sobre Histórias de Vida

\begin{tabular}{l|l|l|l}
\hline AUTORES & ANO & TíTULO & TIPO \\
\hline Eckert-Hoff, B. M. & 2015 & $\begin{array}{l}\text { O discurso do sujeito-professor em formação: } \\
\text { (des)construindo subjetividades }\end{array}$ & Artigo \\
\hline $\begin{array}{l}\text { Bergamaschi, M. A. } \\
\text { and Almeida, D. B. }\end{array}$ & 2013 & $\begin{array}{l}\text { Memoriais escolares e processos de iniciação } \\
\text { à docência }\end{array}$ & Artigo \\
\hline $\begin{array}{l}\text { Almeida, J. S. d. and } \\
\text { Soares, M. }\end{array}$ & 2012 & $\begin{array}{l}\text { Mudaram os tempos; mudaram as mulheres? } \\
\text { Memórias de professoras do Ensino Superior }\end{array}$ & Artigo \\
\hline $\begin{array}{l}\text { López de Maturana } \\
\text { Luna, S. }\end{array}$ & 2010 & $\begin{array}{l}\text { Las complejidades emergentes en las } \\
\text { historias de vida de los buenos profesores"'" }\end{array}$ & Artigo \\
\hline $\begin{array}{l}\text { Cintra, S. C. S. and } \\
\text { Albano, A. A. }\end{array}$ & 2010 & $\begin{array}{l}\text { Memória e (re)criação na formação de } \\
\text { professores: trilhando caminhos }\end{array}$ & Artigo \\
\hline
\end{tabular}

Fonte: elaborado pelas autoras (abril 2020).

Uma pesquisa teve caráter histórico, voltado para a docência no ensino superior (ALMEIDA; SOARES, 2012), e buscou verificar se a escolha pela docência nesse segmento educacional teve influência do movimento feminista das décadas de 1960/70. Os demais trabalhos aqui analisados, e listados na tabela acima, vislumbram na metodologia da história oral um recurso essencial na construção de memoriais e, com eles, possibilitar os sujeitos perceberem elementos que corroboraram na escolha pela docência e nos aspectos que estão presentes em sua prática profissional. Os resultados apontaram a necessidade de as histórias de vida encontrarem seu espaço nos cursos de formação, valorizando as experiências e suas subjetividades na constituição do ser professor. Como ressaltaram os pesquisadores que tiveram seus trabalhos analisados, a leitura das histórias de vida se torna uma importante ferramenta para que o professor perceba o lugar que ocupa, a trajetória percorrida e as complexidades inerentes à constituição de sua identidade profissional. 


\section{Etapa 07: Uma nova palavra-chave}

Após leitura dos trabalhos selecionados, analisando se alguma palavra-chave poderia ter sido incluída no levantamento e que poderia estar relacionada à pesquisa em andamento. Nessa interface entre identidade do pedagogo — perfil midiático — e trajetória formativa, a discussão sobre letramento midiático parecia ser oportuna. $\mathrm{O}$ desenvolvimento de um perfil midiático, tendo como ponto de análise a identidade dos pedagogos em formação constituída pelas suas trajetórias formativas, não parece ser algo possível sem falarmos em letramentos, e aqui, em especial, em letramentos midiáticos.

Quando nos referimos a letramentos, entendemos esse conceito pelo olhar de Lemke (2010). Para ele,

Os letramentos são, em si mesmos, tecnologias e nos dão as chaves para usar tecnologias mais amplas. Eles também produzem uma chave entre o eu e a sociedade: o meio através do qual agimos, participamos e nos tornamos moldados por sistemas e redes 'ecossociais' mais amplos (LEMKE, 2010, p. 456).

Por letramento midiático compreendemos uma expressão "relacionada às habilidades e competências que envolvem o acesso, apropriação, a capacidade de compreensão e análise, consumo, produção, avaliação e a criação de conteúdos em uma variedade de contextos de mídias e linguagens" (CRUZ; SOUZA, 2018, p. 387). Sendo assim, não cremos ser possível falar em identidade midiática na formação do pedagogo sem também fazer inferências ao letramento midiático, já que entendemos ser conceitos que se articulam e se complementam.

Assim, mesmo após a revisão sistemática ter sido concluída, demos um passo atrás e fizemos um levantamento das pesquisas sobre letramento midiático voltadas especialmente à formação inicial de pedagogos. Mantivemos o recorte temporal (2010-2020) e usamos como bases de busca: Scielo, Banco de Teses da Capes e Google Acadêmico.

$\mathrm{Na}$ base Scielo a busca pela palavra-chave "Letramento Midiático" não gerou nenhum resultado. A mudança pelas palavras "Letramento" AND "Professor" gerou 34 trabalhos. Após a análise dos títulos e resumos (tendo como ponto de inclusão somente o que nos motivou nessa busca), selecionamos apenas um artigo, e mesmo 
este tinha como discussão letramento digital, mas foi mantido por, de certa forma, estar articulado diretamente com letramento midiático. Fizemos uma nova busca, usando a combinação das palavras "Letramento" AND "Digital" AND "Professores", e o resultado nos apresentou oito trabalhos. No entanto, após análise dos títulos e resumos, nenhum era resultante de pesquisas voltadas à formação inicial de professores. Insistimos numa nova busca, agora usando palavras em inglês: "Literacity" AND "Media" AND "Teacher", o que também não trouxe resultado algum.

No banco de Teses da CAPES, além do recorte de 10 anos, procuramos por pesquisas exclusivas de programas de pós-graduação da área de Educação. A busca pela palavra-chave "Letramento Midiático" nos apresentou 26 trabalhos. Após a análise dos títulos e resumos, somente dois trabalhos foram selecionados.

A busca pelo Google Acadêmico, usando a palavra-chave Letramento Midiático na Formação de Professores, trouxe um resultado inicial de 8.740 trabalhos. Como o Google disponibiliza os resultados por ordem de relevância e mais fidedignos à palavra-chave, fizemos uma análise dos títulos e resumos dos 70 primeiros trabalhos apresentados. Desses, fizemos a seleção de 14 que, de certa forma, tratavam do letramento midiático na formação de pedagogos. Notamos que os demais trabalhos apresentados na busca após o número 70, não eram fiéis à palavra-chave, apresentando trabalhos sobre letramento, midiático e formação de professores, de forma distinta e separadamente. 
Tabela 11 - Trabalhos selecionados sobre Letramento Midiático

\begin{tabular}{|c|c|c|c|}
\hline AUTORES & ANO & TíTULO & TIPO \\
\hline $\begin{array}{l}\text { SOUZA, T. F. de; } \\
\text { MARQUES, T.R. F.; } \\
\text { CRUZ, D. M. }\end{array}$ & 2013 & $\begin{array}{l}\text { Letramento digital: levantamento de pesquisas } \\
\text { em bases de dados brasileiras }\end{array}$ & Artigo \\
\hline FANTIN, M. & 2012 & $\begin{array}{l}\text { Dimensões da formação cultural e da mídia- } \\
\text { educação na Pedagogia }\end{array}$ & Artigo \\
\hline $\begin{array}{l}\text { BIANCHI, P.; PIRES, } \\
\text { G. L. }\end{array}$ & 2013 & $\begin{array}{l}\text { Formação de professores e letramento digital: } \\
\text { observando caminhos curriculares através da } \\
\text { mídia-educação }\end{array}$ & Artigo \\
\hline $\begin{array}{l}\text { CAPRINO, M. P.; } \\
\text { PESSONI, A.; } \\
\text { APARICIO, A. S. M. }\end{array}$ & 2013 & $\begin{array}{l}\text { Mídia e Educação: A necessidade do } \\
\text { Multiletramento }\end{array}$ & Artigo \\
\hline MOURA, K. M. P. & 2019 & $\begin{array}{l}\text { Revisão sistemática sobre letramento digital na } \\
\text { formação de professores }\end{array}$ & Artigo \\
\hline $\begin{array}{l}\text { MOURA, K. M.; } \\
\text { CARVALHO, M. J.; } \\
\text { MION, M. }\end{array}$ & 2019 & $\begin{array}{l}\text { O letramento digital na formação de professores: } \\
\text { uma revisão sistemática das produções }\end{array}$ & Artigo \\
\hline $\begin{array}{l}\text { MONTANINI, C. A. } \\
\text { M. }\end{array}$ & 2017 & $\begin{array}{l}\text { A cultura digital na formação inicial de } \\
\text { professores da educação básica nas licenciaturas } \\
\text { da UFSM }\end{array}$ & Dissertação \\
\hline $\begin{array}{l}\text { LINHARES, R. N.; } \\
\text { ANDRADE, L. R. S. }\end{array}$ & 2017 & $\begin{array}{l}\text { Educação e as Tecnologias de Informação e } \\
\text { Comunicação: entre descobertas e desafios na } \\
\text { formação inicial de professores }\end{array}$ & Artigo \\
\hline $\begin{array}{l}\text { TELES, E. C.; } \\
\text { BIERWAGEN, G. S. }\end{array}$ & 2019 & $\begin{array}{l}\text { Educação midiática e tecnológica na formação } \\
\text { docente }\end{array}$ & Artigo \\
\hline $\begin{array}{l}\text { SANTOS, J. M. F; } \\
\text { CRUZ, D. M. }\end{array}$ & 2018 & $\begin{array}{l}\text { Produção de disciplina gamificada: uma proposta } \\
\text { de letramento midiático com aproximações entre } \\
\text { mídia-educação e aprendizagem baseada em } \\
\text { jogos }\end{array}$ & Artigo \\
\hline GOMES, S. dos S. & 2016 & $\begin{array}{l}\text { Letramento digital na formação inicial de } \\
\text { professores: a visão de graduandos de } \\
\text { pedagogia EaD }\end{array}$ & Artigo \\
\hline $\begin{array}{l}\text { RIBEIRO, L. A. M.; } \\
\text { GASQUE, K. C. G. D }\end{array}$ & 2015 & $\begin{array}{l}\text { Letramento Informacional e Midiático para } \\
\text { professores do século XXI }\end{array}$ & Artigo \\
\hline FREITAS, M. T. & 2010 & Letramento digital e formação de professores & Artigo \\
\hline LOIOLA, A. V. S. F. & 2019 & $\begin{array}{l}\text { Reportagem televisiva e letramento científico na } \\
\text { formação de pedagogos }\end{array}$ & Dissertação \\
\hline SILVEIRA, R. C. A. & 2017 & $\begin{array}{l}\text { O letramento do professor para a mediação no } \\
\text { processo de desenvolvimento da rádio escolar }\end{array}$ & Dissertação \\
\hline
\end{tabular}

Fonte: elaborado pelas autoras (abril 2020).

No geral, notamos que poucas pesquisas trataram sobre o letramento midiático na formação de professores, em especial, dos pedagogos. Abordam letramento no aspecto linguístico e na área de Letras, e letramento midiático voltado para o cotidiano 
da escola de Educação Básica ou o desenvolvimento do letramento midiático na formação de professores já em exercício.

Assim, ficamos com 18 trabalhos para análise, seguindo o mesmo padrão dos demais textos já analisados nessa revisão sistemática (palavras-chave, objetivos, público-alvo, metodologia e resultados). Deste total, dois trabalhos foram excluídos por já terem sido analisados na busca pela palavra-chave: Perfil Midiático e um por ser repetido, vindo de bases diferentes.

No geral, as pesquisas apresentaram o seguinte cenário: três tiveram como foco a análise de currículo de cursos de graduação em Pedagogia (BIANCHI; PIRES, 2013; MONTANINI, 2017; GOMES, 2016), verificando a presença e como propõem (ou não) o letramento, aqui muito mais voltado para o digital do que o midiático. Outras quatro pesquisas analisaram o percurso de uma determinada disciplina dentro do currículo da Pedagogia (SANTOS; CRUZ, 2018; FANTIN, 2012; LINHARES; ANDRADE, 2017; LOIOLA, 2019), verificando como elas possibilitam aproximações (ou não) com o letramento midiático ou com a mídia-educação.

Outras cinco pesquisas encontradas são teóricas (SOUZA; MARQUES, CRUZ, 2013; MOURA, 2019; MOURA et al., 2019; RIBEIRO; GASQUE, 2015; FREITAS, 2010), sendo duas delas voltadas para a revisão sistemática sobre letramento digital. Outras duas têm como foco a discussão com professores (TELES; BIERWAGEN, 2019; SILVEIRA, 2017) e em uma o diálogo foi com alunos da Educação Básica (CAPRINO et al., 2013. Assim, observamos que, além de termos poucas pesquisas que analisassem a apropriação do letramento midiático na formação inicial de professores, especialmente de Pedagogos, nenhuma delas faz menção ou articulação entre a identidade do pedagogo e a trajetória formativa desses pedagogos em formação.

\section{Etapa 08: Análise geral}

Ao final dessa revisão sistemática, tivemos um total de 75 trabalhos analisados, sendo 59 artigos, seis teses, oito dissertações e dois TCCs (incluídos porque, a princípio, a leitura do resumo indicava que seria feita uma discussão sobre o letramento midiático na formação de pedagogos). Importante destacar que boa parte 
dos artigos são oriundos de pesquisas de mestrado e doutorado, mas como foram os artigos localizados na busca, optamos pela análise deles, até mesmo por trazerem uma síntese do que foi pesquisado.

Tabela 12 - Resultado final dos trabalhos que integraram a Revisão Sistemática

\begin{tabular}{l|l}
\hline Palavra-chave & Quantidade de trabalhos \\
\hline Identidade docente do professor & 19 \\
\hline Representação social do pedagogo & 17 \\
\hline Histórias de vida & 5 \\
\hline Identidade discente & 0 \\
\hline Perfil midiático e cultura digital do professor & 9 \\
\hline Narrativas discentes & 0 \\
\hline Narrativas docentes & 10 \\
\hline Letramento midiático & 15 \\
\hline TOTAL & 75 \\
\hline
\end{tabular}

Fonte: elaborado pelas autoras (abril 2020).

Essa análise cuidadosa das pesquisas realizadas nos últimos dez anos nos mostrou que grande maioria dos estudos realizados, tendo como categoria de análise a Identidade, se dedicou a olhar o pedagogo pelo viés profissional, ou seja, a prática formativa docente desses profissionais e pela análise do currículo dos cursos formativos. Nenhuma das pesquisas buscou em seus estudos a articulação entre a identidade docente e a trajetória formativa desses sujeitos. Da mesma maneira, as pesquisas relacionadas à identidade e letramento midiático também não fazem essa inferência às histórias de vida dos sujeitos investigados com sua apropriação e relação com as mídias e suas linguagens.

\section{Considerações finais}

Ao final da revisão, não foi possível mapear todas as pesquisas realizadas, mas levantamos uma boa base para justificar a relevância da nossa pesquisa em andamento, bem como sua contribuição para o curso de formação inicial de pedagogos. Outro aspecto importante se refere à relevância da narrativa e da história de vida serem adotadas como estratégias metodológicas, visto que conseguem identificar importantes elementos da trajetória formativa dos sujeitos investigados, que não se conseguiria somente com aplicação de questionários e entrevistas semi-estruturadas. 
Além desse mapeamento, a revisão também contribuiu na identificação de autores e dos referenciais teóricos que sustentam essas discussões.

Uma conclusão é a de que pesquisar sobre identidades e sua interface com trajetória formativa são urgentes e necessárias, principalmente quando temos como sujeitos os pedagogos em formação. Discutir sobre identidade midiática dos pedagogos requer levar em consideração a sua relação com as mídias, como estas estiveram presentes em sua trajetória formativa e como contribuíram na constituição da sua identidade. Parece essencial trazer para o debate a representação social que o pedagogo tem sobre essa profissão. São importantes elementos que não podemos discutir separadamente, mas sim, como lentes de um caleidoscópio, que se fundem e se complementam, formando não um único ponto de vista, mas um olhar permeado por diferentes óticas.

O grande diferencial da revisão sistemática é esse, mostrar o quanto já se avançou no debate sobre as temáticas presentes na pesquisa em andamento, bem como perceber lacunas a serem preenchidas, num movimento em espiral, que num crescente vai trazendo importantes elementos para o debate, enaltecendo análises, enriquecendo olhares.

\section{Agradecimentos}

Os autores gostariam de agradecer ao $\mathrm{CNPq}$ pela bolsa produtividade que apoia esse projeto.

\section{Referências}

ABRAHÃO, M. H. M. B. Memoriais de formação: a (re)significação das imagenslembranças/recordações-referências para a pedagoga em formação. Educaşão, Porto Alegre, v. 34, n. 2, p. 165-172, maio/ago. 2011.

ALBERTI, V. Ouvir, contar: textos de história oral. Rio de Janeiro: FGV, 2004.

ALCÂNTARA, W. R. R. A sala de aula foi o meu mundo: a carreira do magistério em São Paulo (1920-1950). Educação e Pesquisa, São Paulo, v. 38, n. 2, p. 289-305, abr./jun. 2012.

ALMEIDA NETO, A. S. Dimensão utópica nas representações sobre o ensino de história: memórias de professores. Educaşão e Sociedade, Campinas, v. 31, n. 110, p. 219-239, jan./mar. 2010.

ALMEIDA, J. S. D.; SOARES, M. Mudaram os tempos; mudaram as mulheres? Memórias de professoras do Ensino Superior. Avaliaģão, Campinas; Sorocaba, v. 17, n. 2, p. 557-580, 2012. 
ALMEIDA, S. R. de; PENSO, M. A.; FREITAS, L. G. de. Identidade docente com foco no cenário de pesquisa: uma revisão sistemática. Educação em Revista, Belo Horizonte, v. 35, 2019.

ARAÚJO, J. L. D.; MAGALHÃES JUNIOR, C. A. de O. As Representações Sociais de Graduandos no Curso de Pedagogia Sobre o "Ser Professor" de Ciências nos Anos Iniciais. Revista Ensino, Educação e Ciências Humanas. Londrina, v. 19, n. 2, p. 252-262, 2016.

AYALA PÉREZ, T. C. Redes sociales e hiperconectividad en futuros profesores de la generación digital. Ciência, Docência y Tecnología, Entre Rios, v. 26, n. 51, 2015.

BALADELI, A. P. D.; von BORSTEL, C. N.; FERREIRA, A. de J. Identidades docentes e diferença no discurso de professores de Língua Inglesa em formação inicial. Revista Portuguesa de Educação, v. 29, n. 1, p. 207-227, 2016.

BARROS, M. E. B. de; BRITO, J. M.; CLEMENTE, O. P. Narrativas da docência: dimensão sensível do trabalho de professores e pesquisadores. Fractal: Revista de Psicologia, Niterói, v. 30, n. 1, p. 30-38, jan./abr. 2018.

BASÍLIO, M. A. T.; MACHADO, L. B. O curso de Pedagogia: nas representações sociais de estudantes em formação. RPD - Revista Profissão Docente, Uberaba, v. 13, n. 28, p. 99-119, jan./jun. 2013.

BATISTA, S. R. Um diálogo entre comunicação e educação: a formação inicial de professores em sociedades midiáticas. Orientadora: Maria Isabel de Almeida. 2012. 220p. Tese (Doutorado em Educação) — Faculdade de Educação, Universidade de São Paulo, São Paulo, 2012.

BERGAMASCHI, M. A.; ALMEIDA, D. B. Memoriais escolares e processos de iniciação à docência. Educação em Revista, Belo Horizonte, v. 29, n. 2, p. 15-41, 2013.

BIANCHI, P.; PIRES, G. L. Formação de professores e letramento digital: observando caminhos curriculares através da mídia-educação. In: CONGRESSO BRASILEIRO DE CIÊNCIAS DO ESPORTE. Anais... Brasília, 2013.

BORGES, F. T. A professora que vemos nos filmes: construção identitária e significados da docência. Caderno Cedes, Campinas, v. 32, n. 88, p. 303-317, set./dez. 2012.

BRANDÃO, D. F.; PARDO, M. B. L. O interesse de estudantes de pedagogia pela docência. Educação e Pesquisa, São Paulo, v. 42, n. 2, p. 313-329, abr./jun. 2016.

BRZEZINSKI, I. Pedagogo: delineando identidade(s). Revista UFG, Goiânia, 2011.

CAPRINO, M. P. et al. Mídia e Educação: A necessidade do multiletramento. Comunicação \& Inovação, São Caetano do Sul, v. 14, n. 26, p. 13-19, jan./jun. 2012.

CARVALHO, R. C. M. de. Formação e constituição da identidade docente de licenciandos de um curso de pedagogia. Orientadora: Edna Maria Querido de Oliveira Chamon. 2012. 169p. Dissertação (Mestrado em Desenvolvimento Humano, Formação, Políticas e Práticas Sociais do IBH) — Instituto Básico de Humanidades, Universidade de Taubaté, Taubaté, 2012.

CASTRO BARBOSA, J. de; TORRES, A. L. M. M.; DANTAS, D. M. P. A formação do pedagogo (a) e o uso das Redes Sociais na sociedade contemporânea: um estudo de caso no curso de Pedagogia da Universidade Federal do Ceará-UFC. In: SIMPÓSIO 
TECNOLOGIAS E EDUCAÇÃO A DISTÂNCIA NO ENSINO SUPERIOR. Anais... Belo Horizonte, 2018.

CERUTTI, E. Concep̧cões do aluno em relação à docência nos cursos de licenciatura em tempos de cibercultura. Orientadora: Lucia Maria Martins Giraffa. 2014. 122p. Tese (Doutorado em Educação) - Faculdade de Educação, Pontifícia Universidade Católica do Rio Grande do Sul, Porto Alegre, 2014.

CHAMON, E. M. Q. D. O. Representações sociais da formação docente em estudantes e professores da Educação Básica. Revista Quadrimestral da Associação Brasileira de Psicologia Escolar e Educacional, São Paulo, v. 18, n. 2, p. 303-312, mai./ago. 2014.

CINTRA, S. C. S.; ALBANO, A. A. Memória e (re)criação na formação de professores: trilhando caminhos. Caderno Cedes, Campinas, v. 30, n. 80, p. 105-111, jan./abr. 2010.

COOK, D. J., MULROW, C. D.; HAYNES, R. B. Systematic reviews: synthesis of best evidence for clinical decisions. Annals of Internal Medicine, v. 126, n. 5, p. 376-380, 1997.

CRUZ, D. M. Letramentos, práticas pedagógicas e formação de professores para as mídias: reflexões sobre a relação entre a cultura digital e a universidade. In: MILL, Daniel; REALI, Aline (Orgs.). Educação a Distância, Qualidade e Convergências: sujeitos, conhecimentos, práticas e tecnologias. São Carlos: EdUFSCar, 2016. p. 177-192.

CRUZ, D. M.; SOUZA, T. F. M. de. Letramento midiático (verbete). In: MILL, D. (Org.). Dicionário crítico de educaşão e tecnologia e de educaşão a distância. Campinas, SP: Papirus, 2018. p. 387-390.

CRUZ, F. M. L.; AGUIAR, M. C. C. de. Trajetórias na identidade profissional docente: aproximações teóricas. Psicologia da Educação, São Paulo, v. 33, p. 7-28, $2^{\circ}$ sem. de 2011.

DALMASO, A. C.; FREITAS, D. S.; SCHMIDT, M. Ser-se rio, vento, mulher, e o que quiser: a individuação e a formação de professores. Educação e Sociedade, Campinas, v. 36, n. 131, p.479-491, abr./jun. 2015.

DANTAS, L. S. C. O faz̧er docente: representações sociais de alunos de curso de pedagogia da UFRN. Orientadora: Erika dos Reis Gusmão Andrade. 2011. 2016p. Dissertação (Mestrado em Educação) - Centro de Ciências Sociais Aplicadas, Universidade Federal do Rio Grande do Norte, Natal, 2011.

DINIZ-PEREIRA, J. E. Lentes teóricas para o estudo da construção da identidade docente. Educação em Perspectiva, Viçosa, v. 7, n. 1, p. 9-34, jan./jun. 2016.

DOMINSCHEK, D. L.; WALOSKI, L. J. R. I. A identidade do pedagogo escolar: notas introdutórias. Revista Intersaberes, Curitiba, v. 8, n. 16, p. 151-175, jul./dez. 2013.

ECKERT-HOFF, B. M. O discurso do sujeito-professor em formação: (des)construindo subjetividades. Caderno Cedes, Campinas, v. 35, n. 95, p. 91-106, jan./abr. 2015.

FANTIN, M. Dimensões da formação cultural e da mídia-educação na pedagogia. EntreVer, Florianópolis, v. 2, n. 3, p. 264-280, jul./dez. 2012. 
FARIA, E. D.; SOUZA, V. L. T. de. Sobre o conceito de identidade: apropriações em estudos sobre formação de professores. Revista Semestral da Associação Brasileira de Psicologia Escolar e Educacional, São Paulo, v. 15, n. 1, p. 35-42, jan./jun. 2011.

FIGUEIREDO, D. D. C.; BONINI, A. Recontextualização e sedimentação do discurso e da prática social: como a mídia constrói uma representação negativa para o professor e para a escola pública. DELTA: Documentação de Estudos em Lingüistica Teórica e Aplicada, v. 33, n. 3, p. $759-786,2017$.

FISCHMAN, G. E.; SALES, S. R. Formação de professores e pedagogias críticas: é possível ir além das narrativas redentoras? Revista Brasileira de Educação, Rio de Janeiro, v. 15 n. 43, jan./abr. 2010.

FREITAS, M. T. Letramento digital e formação de professores. Educação em Revista, Belo Horizonte, v. 26, n. 3, p. 335-352, 2010.

GEBRAN, R. A.; SILVA, N. S.; BARROS, H. F. de. As representações sociais e expectativas dos alunos ingressantes no curso de pedagogia. Comunicações, Piracicaba, v. 22, n. 3, p. 183201, 2015.

GENTILE, M.; LIMA, R. de C. P.; MAZZOTTI, T. Saberes da prática na formação: representações sociais de alunas de pedagogia. Revista Diálogo Educacional, Curitiba, v. 11, n. 33, p. 331-351, maio/ago. 2011.

GOMES, S. dos S. Letramento digital na formação inicial de professores: a visão de graduandos de pedagogia EaD. Educação - Revista do Centro de Educação, Santa Maria, n. 5, set./dez. 2016.

GONÇALVES, K. A. Identidade docente nos artigos da ANPEd - 2010/2014. REBES Revista Brasileira de Ensino Superior, v. 2, n. 3, p. 5-17, jul_/set. 2016.

GONÇALVES, L. D. S. O curso de pedagogia e o processo de construção da identidade do pedagogo. Orientadora: Heloisa Helena Oliveira de Azevedo. 2010. 126p. Dissertação (Mestrado em Educação) - Centro de Ciências Humanas e Sociais Aplicadas, Pontifícia Universidade Católica de Campinas, Campinas, 2010.

GONZALES, N. V. L.; BUENO, J. L. P.; CAETANO, R. F. Os decursos históricos, culturais e legais da constituição da identidade profissional do pedagogo no Brasil. Revista Cocar, Belém, v. 8, n. 15, p. 16-22, jan./jul. 2014.

GORZONI, S. D. P.; DAVIS, C. O conceito de profissionalidade docente nos estudos mais recentes. Cadernos de Pesquisa, São Paulo, v. 47, n. 166, p. 1396-1413, out./dez. 2017.

IZA, D. F. V. et al. Identidade docente: as várias faces da constituição do ser professor. Revista Eletrônica de Educação, São Paulo, v. 8, n. 2, p. 273-292, 2014.

JOSSO, M. C. Experiências de vida e formação. São Paulo: Cortez, 2004.

KNOBLAUCH, A. Religião, formação docente e socialização de gênero. Educação e Pesquisa, São Paulo, v. 43, n. 3, p. 899-914, jul./set. 2017.

LEMKE, J. Letramento metamidiático: transformando significados e mídias. Trabalhos em Linguística Aplicada, Campinas, v. 49, n. 2, jul./dez. 2010. 
LIMA, M. E. C. de C.; GERALDI, C. M. G.; GERALDI, J. W. O trabalho com narrativas na investigação em educação. Educação em Revista, Belo Horizonte, v. 31, n. 1, p. 17-44, jan./mar. 2015.

LIMA, R. de C. P.; SICCA, N. A. L.; DAVID. A. Representações sociais de estudantes de pedagogia sobre o trabalho docente em sua trajetória de formação. Educação e Linguagem, v. 15, n. 25, p. 58-82, jan./jun. 2012.

LINHARES, R. N.; ANDRADE, L. R. S. Educação e as Tecnologias de Informação e Comunicação: entre descobertas e desafios na formação inicial de professores. In: CONGRESSO IBERO-AMERICANO EM INVESTIGAÇÃO QUALITATIVA, 6., 2017, Salamanca. Anais... Salamanca: [s.n.], 2017.

LOIOLA, A. V. S. F. Reportagem televisiva e letramento cientifico na formação de pedagogos. Orientador: Marcus Vinicius da Silva Pereira. 2019. 120p. Dissertação (Mestrado em Educação: Ensino de Ciências) —Instituto Federal do Rio de Janeiro, Nilópolis, 2019.

LOSTADA, L. R. A Jornada do Herói e a Identidade Midiática Docente no contexto da Cultura Digital. Orientadora: Dulce Márcia Cruz. 2020. 295p. Tese (Doutorado em Educação) - Centro de Ciências da Educação, Universidade Federal de Santa Catarina, Florianópolis, 2020.

LUNA, S. L. de M. Las complejidades emergentes en las historias de vida de los buenos professores. Polis, Revista de la Universidad Bolivariana, v. 9, n. 25, p. 255-267, 2010.

MAIA, D. L.; BARRETO, M. C. Ensinar matemática com o uso de tecnologias digitais: uma análise a partir da Representação social de estudantes de Pedagogia. Revista Educação e Cultura Contemporânea, v. 11, n. 24, p. 136-163, 2014.

MALACRIDA, V. A.; MONTI, F. G.; BARROS, H. F. de; RUIZ, A. R. A identidade do curso de pedagogia: uma investigação via história oral. Colloquium Humanarum, v. 10, n. Especial, p. 695-704, jul./dez. 2013.

MANDÚ, T. M. C. Representações sociais do campo de atuação do pedagogo pelos estudantes de pedagogia. Orientador: Maria da Conceição Carrilho de Aguiar. 2013. 160p. Dissertação (Mestrado em Educação) - Faculdade de Educação, Universidade Federal de Pernambuco, CE, 2013.

MARTINS, R. M.; ANUNCIATO, R. M. M. Caminhos de aprendiz de professora: processos identitários em uma comunidade de aprendizagem online. Educação em Revista, Belo Horizonte, n. 34, 2018.

MIRANDA, M. d. C. G. d. Formação de pedagogos em serviço a distância: representações de professores/aprendentes do curso de pedagogia a distância da UFPB Virtual. Orientador: Wilson Honorato Aragão. 2012. 248p. Tese (Doutorado em Educação) - Centro de Educação, Universidade Federal da Paraíba, João Pessoa, 2012.

MONTANINI, C. A. M. A cultura digital na formação inicial de professores da educação básica nas licenciaturas da UFSM. 2017. 226p. Dissertação (Mestrado em Educação) — Faculdade de Educação, Universidade Federal de Santa Maria, Santa Maria, 2017.

MOSCOVICI, S. Representações sociais: investigações em psicologia social. Petrópolis: Vozes, 2011. 
MOURA, K. M.; CARVALHO, M. J. S.; MION, M. O letramento digital na formação de professores: uma revisão sistemática das produções. In: SIMPÓSIO BRASILEIRO DE INFORMÁTICA NA EDUCAÇÃO. Anais... Brasília, 2019.

MOURA, K. M. P. Revisão sistemática sobre letramento digital na formação de professores. Texto Livre, Linguagem e Tecnologia, Belo Horizonte, v. 12, n. 3, p. 128-143, set./dez. 2019.

NÓVOA, A.; FINGER, M. (Org.). O método (auto)biográfico e a formação. Natal, RN: EDUFRN; São Paulo: Paulus, 2010.

OLIVEIRA, D. A. O trabalho docente na América Latina: identidade e profissionalização. Revista Retratos da Escola, Brasília, v. 2, n. 2-3, p. 29-39, jan./dez. 2012.

POLLACK, M. Memória e Identidade Social. Estudos históricos, Rio de Janeiro, v. 5, n. 10, 1992.

PONTES, E. L. F. J. S. P. Cultura digital na formação inicial de pedagogos. Orientadora: Maria Elizabeth de Almeida. 2016. 286p. Dissertação (Mestrado em Educação) — Faculdade de Educação, Pontifícia Universidade Católica de São Paulo, Bagé, 2016.

PORTELLI, A. O que faz a história oral diferente? Projeto História, São Paulo, v. 14, 1997.

RIBEIRO, L. A. M.; GASQUE, K. C. G. D. Letramento Informacional e Midiático para professores do século XXI. Em Questão, Porto Alegre, v. 21, n. 2, p. 203-221, maio/ago. 2015.

ROCHA, B. M. Letramento midiático nas licenciaturas: um estudo com estudantes do curso de Pedagogia da Universidade Federal de Santa Catarina. 2016. 65p. TCC (Graduação em Pedagogia) - Centro de Ciências da Educação, Universidade Federal de Santa Catarina, Florianópolis, 2016.

ROSA, M. I. P.; PAVAN, A. C. Discursos híbridos nas memórias das licenciaturas em ciências em uma instituição universitária. Ciência \& Educaşão, Campinas, v. 17, n. 1, p. 83-96, 2011.

RUEDA ORTIZ, R. Subjetividad y tecnologías de la escritura. La formación en tiempos de poshumanismo. Revista Javeriana, Javeriana, 2016.

SALES, A. d. C. M.; CHAMON, E. M. Q. d. O. Escolha da carreira e processo de construção da identidade profissional docente. Educaşão em Revista, Belo Horizonte, v. 27, n. 3, p. 183210, 2011.

SAMPAIO, R. F. et al. Prática baseada em evidência: buscando informação para fundamentar a prática clínica do fisioterapeuta e do terapeuta ocupacional. Revista Brasileira de Fisioterapia, São Paulo, v. 6, n. 3, p. 8-13, 2002.

SANTOS, J. M. F; CRUZ, D. M. Produção de disciplina gamificada: uma proposta de letramento midiático com aproximações entre mídia-educação e aprendizagem baseada em jogos. Anais da I Jornada ECO de Pesquisas em Desenvolvimento, Florianópolis, p. 65-75, 2018.

SARAIVA, A. C. L. C.; AQUINO, S. L. O pedagogo e seus espaços de atuação nas Representações Sociais de egressos do Curso de Pedagogia. Educação em Perspectiva, Viçosa, v. 2, n. 2, p. 246-268, jul./dez. 2011.

SERODIO, L. A.; PRADO, G. d. V. T. Escrita-evento na radicalidade da pesquisa narrativa. Educação em Revista, Belo Horizonte, n. 33, 2017. 
SILVA, D. N. H.; SIRGADO, A. P.; TAVIRA, L. V. Memória, narrativa e identidade profissional: analisando memoriais docentes. Caderno Cedes, Campinas, v. 32, n. 88, p. 263283, set./dez. 2012.

SILVA, S. S. L. D.; BONFIM, M. N. B. Representações sociais e identidade docente: um estudo com professores-alunos do PROFEBPAR/UFMA. Revista Educação e Emancipação, São Luís, v. 11, n. 2, p. 172-193, mai./ago. 2018.

SILVEIRA, R. C. A. O letramento do professor para a mediação no processo de desenvolvimento da rádio escolar. Orientadora: Fabiana Giovani. 2017. 127p. Dissertação (Mestrado em Línguas) Ensino de Línguas, Universidade Federal do Pampa, Bagé, RS, 2017.

SIPPE, F. E. Produção de sentidos sobre a construção da identidade social do pedagogo: relatos de educadores. Orientador: Eraldo Carlos Batista. 2018. 66p. Trabalho de Conclusão de Curso (Graduação em Pedagogia) - Faculdade de Educação, Fundação Universidade Federal de Rondônia, Rolim de Moura, 2018.

SOUZA, P. R. F. d. A Representação Social da docência pelos alunos do curso de Pedagogia da Faculdade de Educaşão da Universidade Federal do Amazonas: um diálogo com Bourdieu em um estudo do percurso no processo de formação. Orientadora: Arminda Rachel Botelho Mourão. 2015. 191p. Tese (Doutorado em Educação) — Faculdade de Educação, Universidade Federal do Amazonas, Manaus, 2015.

SOUZA, T. F. M. de; MARQUES, T. R. F.; CRUZ, D. M. Letramento digital: levantamento de pesquisas em bases de dados brasileiras. Revista Novas Tecnologias na Educação, Porto Alegre, v. 11, n. 3, 2013.

TELES, E. C.; BIERWAGEN, G. S. Educação midiática e tecnológica na formação docente. In: CONGRESSO BRASILEIRO DE CIÊNCIAS NA COMUNICAÇÃO, 42., 2019, Belém. Anais... Belém: [s.n.], 2019.

VENTURA, L. O Voo da Fênix: narrativas de travessias de identidade de egressas de educação a distância. Orientadora: Dulce Márcia Cruz. 2018. 258p. Tese (Doutorado em Educação) - Centro de Ciências da Educação, Universidade Federal de Santa Catarina, Florianópolis, 2018.

WEBSTER, J.; WATSON, J. T. Analyzing the past to prepare for the future: writing a literature review. MIS Quarterly \& The Society for Information Management, v. 26, n. 2, p. 13-23, 2002. 